\title{
Bioaerosols in Indoor Environment - A Review with Special Reference to Residential and Occupational Locations
}

\author{
Jyotshna Mandal and Helmut Brandl*
}

Institute of Evolutionary Biology and Environmental Studies, University of Zurich, Switzerland

\begin{abstract}
Bioaerosols such as bacterial and fungal cells and their spores are - along with non-biological particles - part of indoor airborne particulate matter and have been related since a long time to health issues of human beings as well as flora, and fauna. To identify the different risks and to establish exposure thresholds, microbiology of air samples from a series of indoor environments must be characterized, i.e. the different microorganisms (bacteria and fungi) must be identified and quantified. This review discusses the techniques of air sampling and sample analysis. In addition, a literature study has been performed regarding the levels of these microorganisms in various indoor occupational (e.g., schools, offices, hospitals, museums) and dwelling environments. These results will provide a significant scientific basis for indoor air quality control and help in elaborating risk prevention programs for workers and dwellers. This review shall contribute to the knowledge of identification and quantification of airborne microbial constituents in various indoor environments. Combining the indoor microbial load data with data from studies focusing on health effects caused by inhalation of specific airborne microorganisms will allow the evaluation of various risks to which inhabitants are exposed.
\end{abstract}

Keywords: Bioaerosols, microbial diversity, sampling, monitoring, occupational environment, maximum acceptable values.

\section{INTRODUCTION}

Aerosols are liquid or solid particles suspended in a gaseous medium with size ranges from 0.001 to $100 \mu \mathrm{m}$ [1]. Bioaerosols consists of aerosols containing microorganisms (bacteria, fungi, viruses) or organic compounds derived from microorganisms (endotoxins, metabolites, toxins and other microbial fragments) [2]. Aerosol particles of biological origin (cells, cell fractions or organic matter of animal, plant and microbial origin) form a significant portion of atmospheric aerosols, sometimes reaching close to $50 \%$ numerically of all aerosol particles [3]. Bioaerosols vary in size $(20 \mathrm{~nm}$ to $>100 \mu \mathrm{m})$ and composition depending on the source, aerosolization mechanisms, and environmental conditions prevailing at the site [4]. The inhalable fraction (PM 2.5 ) is of primary concern because it is the most susceptible portion of the bioaerosols to reach the deeper parts of the respiratory system [5]. Because of their light weight, airborne particles are readily transported, transferred, and displaced from one environment to the other. Indoor air contains a complex mixture of bioaerosols such as fungi, bacteria and allergens along with non-biological particles (e.g., dust, smoke, particles generated by cooking, organic and inorganic gases) [6]. Airborne microorganisms might pose an environmental hazard when present in high concentrations in indoor environments resulting in health problems [7].

When bioaerosols are measured at sampling sites, monitoring of environmental factors can be a useful tool to

*Address correspondence to this author at the University of Zurich Institute of Evolutionary Biology and Environmental Studies Winterthurerstrasse 190 CH-8057 Zurich Switzerland; Tel: +41 (0)44 63561 25;

Fax: +41 (0)44 63557 11; E-mail: helmut.brandl@ieu.uzh.ch explain possible bioaerosol sources. There are some evidences that show the significant associations between bioaerosols levels and some environmental factors, such as temperature and relative humidity [7]. Since most of the bacteria and fungi need specific environmental conditions to grow and propagate, their levels are strongly affected by these factors. In some cases, heating, air-conditioning or ventilating systems may provoke fluctuations of temperature and relative humidity, such as in museums, which can cause serious harm [8].

In non-industrial indoor environments, one of the most important sources of airborne bacteria is the presence of human beings [9]. In particular activities like talking, sneezing, coughing, walking, washing and toilet flushing can generate airborne biological particulate matter. Food stuffs, house plants and flower pots, house dust, pets and their beddings, textiles, carpets, wood material and furniture stuffing, occasionally release of various fungal spores into the air $[10,11]$. According to several studies, the moisture content of building material, relative humidity and temperature [12, 13], outdoor concentrations, air exchange rates [14] and number of people and pets [15] significantly affect the levels of indoor bioaerosols. Generally higher concentrations of bioaerosols have been reported from warmer than cooler climates. Moreover, housing conditions, the activities and life style of occupants considerably contribute to the varying concentrations [16]. Under normal conditions, bacteria and fungi do not notably grow in building materials or structures or on indoor surfaces, mainly because of lack of moisture [17].

The indoor air is a very dynamic system in which particles of biological and non-biological origin are distributed and displaced. Studies have been carried out to check 


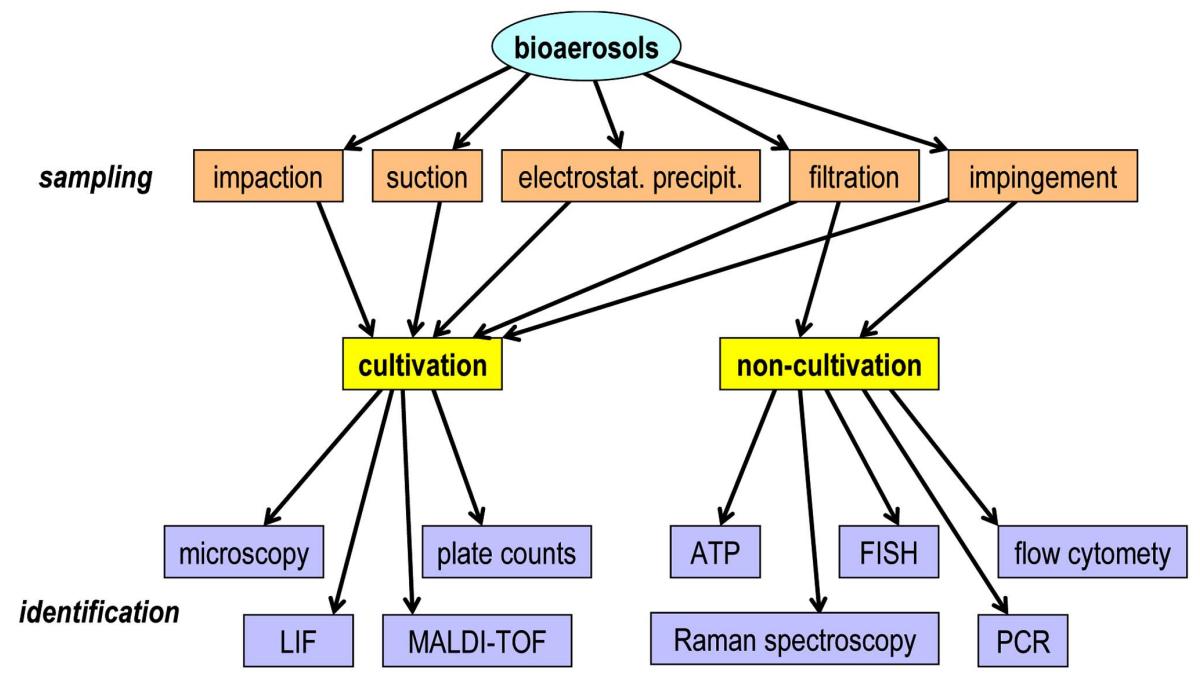

Fig. (1). Flow chart indicating selected examples of fungal and bacterial bioaerosol sampling methods and identification techniques described in the text (see text for abbreviations) in relation to sample processing (i.e., cultivation or non-cultivation).

the indoor air quality (IAQ) as it is an increasingly important issue for occupational and public health [18]. The sampling and analysis of airborne microorganisms in indoor air has received attention in recent years [19-21]. Bioaersosols contribute to about 5 to $34 \%$ of indoor air pollution [22]. The source of bioaerosols in indoor air includes furnishing and building materials, microbiological contamination within the walls and ceilings and floor activities. Another significant source of airborne indoor bacteria are occupants [21, 23]. Sources of indoor bioaerosols are often located outdoors and particles are transferred to the inside through openings of the building envelope (windows, doors). However, one of the most important factors affecting indoor air quality is how the building is heated, ventilated, air-conditioned [24] and its occupancy [25]. These factors can be used to model and predict indoor bioaerosol concentration [14, 26].

Microbiological air quality is an important criterion that must be taken in to account when indoor workplaces places are designed to provide a safe environment. This review provides information on what is currently known on various indoor air concentration of microorganisms and describes bacterial and fungal loads for different kinds of indoor environment (such as in occupational and dwelling places). A brief description of various sampling and analysis methods used to characterize airborne microorganisms is also given.

\section{COLLECTION OF AIR SAMPLES}

The devices used to sample airborne fungi and bacteria mainly rely on three different principles namely, impaction, impingement and filtration which are described below (Fig. 1).

Impactors - Solid media such as agar are used to collect bioaerosols by impaction sampling. Cheap costs of samplers and their easiness to handle are major advantages [27]. Typically, samplers are equipped with a fan transferring air through a perforated template (sieve samplers) or a narrow slit (slit samplers) directly onto standard agar plate containing a suitable agar growth medium. Impaction velocity is determined by the flow rate and nozzle diameter or the width of the slit and is the range of $40 \mathrm{~km} / \mathrm{h}$. When hitting the col- lection surface, the air sampled changes direction perpendicularly and any suspended particles are tangentially impacting onto the agar surface. Agar plates can be removed when appropriate volumes of air have been sampled and incubated directly under appropriate conditions without further treatment. The number of visible colonies can be counted by visual inspection after incubation resulting in a direct quantitative estimate of the number of culturable microorganisms in the sampled air.

Rotorod sampler [28] is used to know the particles quantitatively recovered per unit of air sampled. The rotorod sampler [29] is a volumetric, rotation impaction device capable of quantitatively sampling airborne particles in the size range of 1 to $100 \mu \mathrm{m}$ at sampling rates up to 120 liters per minute. Its trapping efficiency is nearly $100 \%$ for particle size larger than $15 \mu \mathrm{m}$ in diameter in still air. Rotorod sampler from Sampling Technologies Inc. USA is popularly used.

The "Andersen sampler" is one of the best known impactors. It consists of a multi-stage cascade sieve unit that uses perforated plates with progressively smaller holes at each stage, allowing particles to be separated according to size. A statistical "positive hole correction" is needed to evaluate highly loaded plates [30,31]. Another well known instrument is the Casella slit sampler. A turntable - on which an agar plate is placed - is positioned below a slit. When air is drawn through the slit, the agar plate rotates, so that particles are evenly dispersed over the agar surface [32].

MAS-100eco single stage impaction samplers are used for the collection of bioaerosols by some authors [11,33]. An amount of 50 to 5001 of air (or less depending on the sampling location) can be collected in time intervals of 3 to 5 minutes. Standard $90 \mathrm{~mm}$ Petri dishes containing different solid growth media can be used with the impaction sampler [27]. Nutrient agar is used for the determination of culturable bacterial strains. For determination of total number of culturable bacteria, tryptic soy agar is used. MacConkey Agar is use to determine Gram-negative bacteria [34]. For the determination of fungi (moulds and yeasts) malt extract agar has been frequently used. 
Impingers - In contrast to impactors, particle collection by impingement is based on liquid media. Typically, sampled air is drawn by suction through a narrow inlet tube into a small flask containing the collection medium accelerating the air collected towards the surface of the collection medium. Flow rate is determined by the diameter of the inlet nozzles. When the air hits the surface of the liquid any suspended particles are impinged into the collection liquid. Once the sampling is complete, aliquots of the collection liquid can be cultivated in appropriate growth media to enumerate viable microorganisms. Since the sample volumes and sampling times can be defined, results allow quantitative determinations.

The "BioSampler" liquid impinger (SKC, Eight Four, PA, USA) is popularly used. The sampler is an all-glass, swirling aerosol collector consisting of an air inlet, three tangentially arranged nozzles and a collection vessel [35]. The AGI-30 sampler (Ace Glass Inc., N.J., USA) is a cheap, but less efficient impinger developed to sample bioaerosols [36, 37].

Suction sampler - Suction samplers are based on the suction of a certain volume of air according to a known velocity and for a chosen duration on each trapping. Ogden [38] designed a volumetric sampler, based on aerodynamic principles. There are several suction samplers available like Hirst automatic volumetric sampler [39], Burkard seven day volumetric sampler, Burkard personal slide sampler, Burkard Petriplate sampler (Burkard Inc., Burkard Manufacturing Co. Ltd., England) [40].

Filtration samplers - With this method, particles are removed from the air by suction filters of definite pore mesh size, which offers volumetric potential, appropriate for smaller aerosol classes and where ambient velocities are low. Air is drawn by a vacuum line through a membrane filter made of glass fibre, polyvinylchloride (PVC), polycarbonate or cellulose acetate (which can be incubated directly by transferring onto the surface of agar growth media), or gelatine which can be dissolved liquid cultures. However, filtration is less convenient than impaction-based sampling and may cause dehydration stress in the trapped microorganisms. Dehydration stress depends on sampling time and while gelatine filters offer a more "friendly" environment for the microorganisms, microorganisms can still suffer from dehydration stress compared to impactors [41]. Use of polyurethane foam inserts allows collection of bioaerosols according to the size fractions [42]. Filter samples allow sampling for longer times without the loss of collection efficiency compared to impactors and impingers. Dehydration due to longterm sampling may prevent from determining colony forming units (CFUs), but one can use molecular analysis techniques.

In the past few years, portable (battery-operated) impactors have become popular for the collection of culturable bioaerosols. Such devices do not require heavy external pumps and feature high sampling flow rates. Various performance parameters of a series of portable impactors have been compared when collecting polystyrene latex particles and biological particles under controlled laboratory conditions [43-45]. Results suggested that when impactors are used for the collection of airborne bacteria and fungi, sam- pling times should be kept as short as possible to minimize under-representation of airborne microorganism concentration. In a field study involving the same portable impactors it was found that a majority of them underperformed compared to a BioStage impactor (SKC Inc., Eighty Four, PA), which is an equivalent to the Andersen N-6 viable impactor [41].

Electrostatic methods- Mainelis et al. [46] developed a bioaeorosol sampler, called electrostatic precipitator, which utilizes an electric field to deposit charges on bacterial samples and a solid agar as bacterial growth media. In this device, two ionizers in the inlet charge the incoming biological particles if they carry an insufficient charge for efficient collection. The particles are then subjected to a precipitating electric field and are collected onto two square agar plates placed one after the other along the flow axis. In electrostatic precipitators, the particle velocity component perpendicular to the collection medium is two to four orders of magnitude lower than that in bioaerosol impactors and impingers operating at comparable sampling flow rates [47]. Therefore, the electrostatic precipitation technique is potentially less damaging to the microorganisms. In addition, instruments based on this technique can operate at low power input. Lowpower bioaerosol collectors are of interest to bioaerosol monitor developers and field practitioners, especially in situations where low-power-consuming monitors are placed in and around buildings and installations to serve as warning devices against bioterrorism [48].

The recovery efficiency varies depending on the air sampler used. It has been found approximately $75 \%$ of the Gram-negative bacterium Pantoea agglomerans is reaerosolized and displaced from the sampler during use of an AGI-30 sampler, whereas only $20 \%$ is lost using the SKC Biosampler [49]. This was also shown with standardized particles of non-biological origin such as monodisperse polystyrene beads [50]. In swirling airflow collectors (e.g. BioSampler) re-aerosolization is reduced and minimized due to the nozzle-guided tangential air flow in the sampling vessel resulting in reduced shear forces [50]. It has been shown that collecting air samples by filtration usually resulted in a recovery efficiency of only approximately 50\% [49]. However, a differentiation of sampling efficiency and culturability of microbes collected is needed. In addition, other studies also demonstrated that recovery strongly depended on the target organism [51]. As example, E. coli could not be recovered by filtration because of desiccation, whereas sampling efficiency for Bacillus subtilis was comparable to efficiencies of impingement or impaction samplers. The culturability of yeast cells was much better after collection by impingement rather than filtration on nuclepore or gelatine filters [52]. However, a dependence on environmental parameters such as relative humidity was observed. It is generally accepted that prolonged sampling times (e.g. >60 min) usually decrease recovery efficiencies in both impactors and impingers due to several factors such as desiccation, shear forces, or re-aerosolization $[49,52]$. Recent research shows that even short sampling times affect the recovery of collected microorganisms when sampled with impactors [53]. As conclusion, it is therefore of fundamental importance that when comparing culturable bioaerosol concentrations determined in different studies, air sampling techniques as well as the methods used for identification (e.g. growth medium for 
cultivation) have to be similar or even identical [54]. In addition, multi-investigator round-robin testing might be carried out for better understanding of sampling biases.

\section{PARTICLE COUNTING}

Laser particle counters are used to determine particle numbers [55, 56]. Particle size determination is based on optical particle counting by light scattering (refraction, reflection, and diffraction) from single particles flowing out of a nozzle. Both the number and size of particles can be simultaneously determined.

Several studies have demonstrated that there is a correlation between the total particle numbers of a specific size (e.g. 1 to $5 \mu \mathrm{m}$ ) and the number of fungal or bacterial colony forming units [55-58]. Particle counting can be done on a fast basis (using appropriate equipment) without the need of applying air sampling and microbial identification techniques (e.g. cultivation, DNA extraction and sequencing). The simple counting of particles of a certain size class might give a first "quick and dirty" approximation of a possible microbial contamination of the air. It has been stated that "total particles might be used to trace the viable bioaerosol particles" [57]. Bacteria might have correlation with numbers of all particle size ranges assessed, whereas fungal colony forming units were correlated only to size range 1 to 5 $\mu \mathrm{m}$ [58]. The number of culturable fungi correlated well with total number of particles $<2.5 \mu \mathrm{m}$ [6]. However, other studies showed that also bacterial numbers are only correlated to size rages of 1 to $5 \mu \mathrm{m}$ and $>5 \mu \mathrm{m}$ [56].

\section{IDENTIFICATION OF AIRBORNE BACTERIA AND FUNGI}

A wide range of analytical methods is used to determine the presence of airborne microorganisms and to characterize composition and activities of these microbial communities, many of the methods covering well-proven classical microbial techniques such as e.g. microscopy or cultivation (Fig. 1) $[59,60]$. Current methods have been applied both on a non-molecular and molecular (DNA- or RNA-based) level. In addition, spectroscopic techniques based e.g. on the mass of fragmented biomolecules, on molecular vibrations of chemical bonds of biomolecules, or on fluorescence of cellular constituents, all in combination with chemometric data analysis have been introduced.

Microscopy - Microscopic examination and enumeration of airborne biological particles are done with air samples that are drawn on glass slides or filters fitted on to samplers. For most microorganisms, species identification is not possible without processing the sample with a technique designed to identify taxa or species. To facilitate the description of fungal spores several stains that differentiate fungal spores from debris are available [61]. They are identified by morphology and a certain level of expertise is also required. In combination with classical microscopy, fluorescent probes are applied to stain and determine specific bacterial groups or even species in a sample $[62,63]$. Total number of bacteria are normally determined after staining with a fluorescent dye such as DAPI (4, 6 diamidino-2-phenylindol) or SYBR Green (asymmetrical cyanine dye) that bind to DNA. Acridine Orange is used to detect viable cells. As example, fluorescence in situ hybridisation (FISH) using specific molecular probes binding to ribosomal RNA of intact cells has been used to detect airborne microbes such as eubacteria or more specifically - Pseudomonas aeruginosa, P. fluorescens, $P$. mendocina and Comamonas acidovorans in swine barns [64].

Cultivation - Studying microbial biodiversity in air samples is mostly relied upon on culturing for the quantification and identification of airborne bacteria and fungi. Microorganisms that are collected on a nutrient agar surface by impaction can be cultured directly, while organisms collected on liquid or on a filter are transferred to a culture medium. Colony-forming units (cfu) on solid growth media are counted after visual inspection. However, since microorganisms exhibit a wide range of nutritional requirements, no formulation is capable of culturing every type of organism [65]. Therefore, a common strategy in bioaerosol monitoring is to use general media which promotes the growth of many diverse species. Another strategy is to use several media and incubation conditions (temperature, incubation time, $\mathrm{pH}$, nutrients, antibiotics, etc.) specific to the particular microorganisms to be analysed [66]. Many investigators have conducted studies for which the goal was to evaluate microbial load in various indoor environments such as indoor occupational, indoor agricultural, and in dwelling places. The majority of these studies used culture based techniques to isolate, quantify and identify airborne microorganisms. Table $\mathbf{1}$ gives the concentrations of various bacteria, fungi and viruses obtained in these indoor environments. Generally it is necessary to perform replicate sampling using different culture media or to divide samples for inoculation on to multiple types of nutrient media. Several broad spectrum media have been evaluated for culturable airborne fungi such as malt extract agar, Rose Bengal agar and DG-18 agar [33, 6769]. For the cultivation of bacteria, several broad spectrum media such as tryptic soy agar or nutrient agar are commonly used $[27,56]$. It has to be stressed, however, that only a small fraction of airborne microbes in a sample can be cultivated, resulting in numbers usually one or two orders less than determined by cultivation-independent methods [70]. This cultivable fraction is a part of the live microbes in a sample, whereas total numbers include dead microbes too. These can be identified by staining with specific dyes.

Flow cytometry - Flow cytometric analysis on air samples is usually performed after air collection by impingement. In flow cytometry a suspension of cells is passed rapidly through a capillary in front of a measuring window. Light emitted from a source is scattered by particles in the liquid and several particles such as size, shape, biological and chemical properties can be measured simultaneously. Autofluorescence or indirect fluorescence of cells affector labelling is also used to detect cells. In addition, specific dyes such as e.g. DAPI, Acridine Orange, SYTO, TO-PRO or wheat germ agglutinin (WGA) are applied to determine total number and live/dead-ratios of microorganisms, respectively [71]. Fluorescence in situ hybridisation (FISH) and flow cytometry might be combined resulting in a more powerful analysis of air samples [70].

Polymerase chain reaction (PCR) - PCR technique has been used to detect and quantify microorganisms from 
Table 1. Airborne Microorganisms (Bacteria and Fungi) and their Concentrations in Various Selected Indoor Locations. SM: Sampling Method; ID: Identification Method; GM: Growth Medium (1 Blood Agar; 2 Czapek-Dox Agar; 3 DG-18 Agar: Dichloran Glycerol-18 Agar; 4 Endo Agar; 5 MacConkey Agar; 6 MEA: Malt Extract Agar; 7 NA: Nutrient Agar; 8 Peptone Dextrose Agar; 9 Potato Dextrose Agar; 10 PYA: Potato Yeast Agar; 11 PCA: Plate Count Agar; 12 Rose Bengal Agar; 13 Sabouraud Dextrose Agar; 14 Sheep Blood Agar; 15 TSA: Tryptic Soy Agar; 16 yeast extract agar); Temp: Temperature at sampling site $\left({ }^{\circ} \mathrm{C}\right)$; RH: Relative Humidity in \%; cfu: Colony Forming Units; BD: Below Detection Limit; NA: Not Applicable; ND: Not Determined; NS: Not Specified

\begin{tabular}{|c|c|c|c|c|c|c|c|c|c|c|c|c|c|c|}
\hline \multirow[t]{2}{*}{ Location } & \multirow[t]{2}{*}{ SM } & \multirow[t]{2}{*}{ ID } & \multirow[t]{2}{*}{ GM } & \multirow{2}{*}{$\begin{array}{c}\text { Temp } \\
\left({ }^{\circ} \mathrm{C}\right)\end{array}$} & \multirow{2}{*}{$\begin{array}{l}\text { RH } \\
(\%)\end{array}$} & \multicolumn{4}{|c|}{ Bacterial Counts $\left(\mathbf{c f u} / \mathbf{m}^{3}\right)$} & \multicolumn{4}{|c|}{ Fungal Counts $\left(\mathbf{c f u} / \mathbf{m}^{3}\right)$} & \multirow[b]{2}{*}{ Ref. } \\
\hline & & & & & & Ave & Min & Max & Dominant Genus & Ave & Min & Max & Dominant Genus & \\
\hline Hospital & $\begin{array}{c}\text { Single stage } \\
\text { Andersen sampler }\end{array}$ & Cultivation & $\begin{array}{l}6, \\
15\end{array}$ & NS & NS & ND & 2 & 423 & NA & $\mathrm{ND}$ & 1 & 3115 & ND & [106] \\
\hline Hospital & $\begin{array}{l}\text { MAS-100 sampler, } \\
\text { single stage } \\
\text { Anderson sampler }\end{array}$ & Cultivation & $\begin{array}{l}6 \\
10\end{array}$ & NS & NS & $\mathrm{ND}$ & ND & ND & NA & 200 & 10 & 85 & ND & [161] \\
\hline Hospital & MAS-100 sampler & Cultivation & 6,7 & NS & NS & ND & ND & ND & NA & 96 & ND & ND & $\begin{array}{c}\text { Alternaria } \\
\text { Aspergillus } \\
\text { Cladosporium } \\
\text { Penicillium }\end{array}$ & [123] \\
\hline Hospital & $\begin{array}{l}\text { 6-stage Andersen } \\
\text { sampler }\end{array}$ & $\begin{array}{l}\text { Cultivation } \\
\text { Microscopy }\end{array}$ & 7 & $23-28$ & $72-80$ & ND & 35 & 728 & NA & ND & $\mathrm{ND}$ & ND & NA & [107] \\
\hline Hospital & $\begin{array}{c}\text { Six stage } \\
\text { Andersen sampler }\end{array}$ & $\begin{array}{c}\text { Cultivation } \\
\text { Molecular } \\
\text { identification }\end{array}$ & $\begin{array}{c}1, \\
12 \\
15\end{array}$ & NS & NS & ND & 38 & 131 & $\begin{array}{c}\text { Bacillus } \\
\text { Micrococcus } \\
\text { Staphylococcus }\end{array}$ & $\mathrm{ND}$ & 14 & 611 & $\begin{array}{c}\text { Alternaria } \\
\text { Aspergillus } \\
\text { Cladosporium } \\
\text { Penicillium }\end{array}$ & [68] \\
\hline Hospital & $\begin{array}{l}\text { 6-stage cascade } \\
\text { impactor }\end{array}$ & $\begin{array}{c}\text { Cultivation } \\
\text { Biochemical } \\
\text { identification }\end{array}$ & $\begin{array}{l}6, \\
15\end{array}$ & NS & NS & 372 & ND & ND & $\begin{array}{c}\text { Bacillus } \\
\text { Corynebacterium } \\
\text { Micrococcus } \\
\text { Staphylococcus }\end{array}$ & 156 & ND & ND & $\begin{array}{c}\text { Alternaria } \\
\text { Aspergillus } \\
\text { Cladosporium } \\
\text { Penicillium }\end{array}$ & [108] \\
\hline Hospital & $\begin{array}{l}\text { Burkard personal } \\
\text { Petri plate sampler }\end{array}$ & Microscopy & 12 & NS & NS & ND & ND & ND & NA & 5437 & 3419 & 7701 & $\begin{array}{l}\text { Aspergillus } \\
\text { Cladosporium } \\
\text { Geotrichum } \\
\text { Penicillium }\end{array}$ & [69] \\
\hline Museum & $\begin{array}{l}\text { 6-stage Andersen } \\
\text { sampler }\end{array}$ & Cultivation & $\begin{array}{l}6, \\
15\end{array}$ & NS & NS & 714 & 545 & 883 & $\begin{array}{c}\text { Bacillus } \\
\text { Corynebacterium } \\
\text { Micrococcus } \\
\text { Staphylococcus }\end{array}$ & 39 & 28 & 49 & $\begin{array}{l}\text { Acremonium } \\
\text { Aspergillus } \\
\text { Penicillium } \\
\text { Rhizopus }\end{array}$ & [109] \\
\hline Museum & $\begin{array}{l}\text { Gravitational } \\
\text { sedimentation }\end{array}$ & Cultivation & 7,8 & NS & NS & 50 & $\mathrm{ND}$ & $\mathrm{ND}$ & $\begin{array}{l}\text { Arthrobacte } \\
\text { Bacillus } \\
\text { Micrococcus } \\
\text { Pseudomonas } \\
\text { Staphylococcus }\end{array}$ & 30 & $\mathrm{ND}$ & $\mathrm{ND}$ & $\begin{array}{l}\text { Alternaria } \\
\text { Aspergillus } \\
\text { Penicillium }\end{array}$ & [110] \\
\hline Office & $\begin{array}{l}\text { Single stage } \\
\text { Andersen } \\
\text { sampler }\end{array}$ & $\begin{array}{l}\text { Cultivation, } \\
\text { microscpy }\end{array}$ & 3,6 & $18-23$ & $9-60$ & $\mathrm{ND}$ & $\mathrm{ND}$ & $\mathrm{ND}$ & NA & 22 & 1 & 618 & $\begin{array}{c}\text { Alternaria } \\
\text { Aspergillus } \\
\text { Cladosporium } \\
\text { Penicillium }\end{array}$ & [67] \\
\hline Office & $\begin{array}{l}\text { Burkard portable } \\
\text { sampler, } \\
\text { 2-stage Andersen } \\
\text { impactors }\end{array}$ & NS & NS & 21-35 & $37-50$ & $\mathrm{ND}$ & ND & $\mathrm{ND}$ & ND & 431 & 106 & 1113 & $\begin{array}{l}\text { Alternaria } \\
\text { Aspergillus } \\
\text { Cladosporium } \\
\text { Curvularia } \\
\text { Penicillium }\end{array}$ & [67] \\
\hline Office & $\begin{array}{l}\text { Single stage } \\
\text { Andersen N-6 } \\
\text { samplers }\end{array}$ & $\begin{array}{l}\text { Cultivation, } \\
\text { microscopy }\end{array}$ & 3,6 & 23 & 33 & ND & $\mathrm{ND}$ & $\mathrm{ND}$ & NA & 42 & 1.1 & 618 & $\begin{array}{c}\text { Alternaria } \\
\text { Aspergillus } \\
\text { Cladosporium } \\
\text { Penicillium }\end{array}$ & [132] \\
\hline Office & $\begin{array}{l}\text { 2-stage Anderson } \\
\text { sampler }\end{array}$ & Cultivation & 10 & $21-23$ & $25-29$ & 1987 & 900 & 3100 & $\begin{array}{l}\text { Arthrobacter } \\
\text { Bacillus } \\
\text { Micrococcus }\end{array}$ & $\mathrm{ND}$ & $\mathrm{ND}$ & $\mathrm{ND}$ & NA & [113] \\
\hline Office & $\begin{array}{l}\text { Single stage, } \\
\text { multiple hole } \\
\text { impactors }\end{array}$ & NS & NS & NS & NS & ND & ND & 116 & $\begin{array}{c}\text { Gram-positive } \\
\text { cocci }\end{array}$ & $\mathrm{ND}$ & ND & $\mathrm{ND}$ & NA & [112] \\
\hline
\end{tabular}


Table 1. count..

\begin{tabular}{|c|c|c|c|c|c|c|c|c|c|c|c|c|c|c|}
\hline \multirow[t]{2}{*}{ Location } & \multirow[t]{2}{*}{ SM } & \multirow[t]{2}{*}{ ID } & \multirow[t]{2}{*}{ GM } & \multirow{2}{*}{$\begin{array}{l}\text { Temp } \\
\left({ }^{\circ} \mathrm{C}\right)\end{array}$} & \multirow{2}{*}{$\begin{array}{l}\mathrm{RH} \\
(\%)\end{array}$} & \multicolumn{4}{|c|}{ Bacterial Counts $\left(\mathbf{c f u} / \mathbf{m}^{3}\right)$} & \multicolumn{4}{|c|}{ Fungal Counts $\left(\mathbf{c f u} / \mathbf{m}^{3}\right)$} & \multirow[b]{2}{*}{ Ref. } \\
\hline & & & & & & Ave & Min & $\operatorname{Max}$ & Dominant Genus & Ave & Min & $\operatorname{Max}$ & Dominant Genus & \\
\hline Office & $\begin{array}{c}\text { MAS-100 } \\
\text { samplers, single } \\
\text { stage Anderson } \\
\text { sampler }\end{array}$ & Cultivation & 6,10 & NS & NS & ND & $\mathrm{ND}$ & ND & NA & ND & 10 & 700 & ND & {$[161]$} \\
\hline Office & MAS-100 & Cultivation & 4,9 & 24 & 63 & ND & 400 & 500 & NA & ND & ND & ND & NA & {$[11]$} \\
\hline Office & Andersen sampler & $\begin{array}{l}\text { Semi automa- } \\
\text { tic counter }\end{array}$ & $\begin{array}{l}10, \\
13 \\
14\end{array}$ & 21 & 30.7 & 135 & 44 & 283 & $\begin{array}{c}\text { Bacillus } \\
\text { Micrococcus } \\
\text { Staphylococcus }\end{array}$ & 113 & 18 & 274 & $\begin{array}{l}\text { Aspergillus } \\
\text { Cladosporium } \\
\text { Penicillium } \\
\text { Ulocladium }\end{array}$ & [111] \\
\hline Office & Impactor Sampler & $\begin{array}{c}\text { Metabolic } \\
\text { fingerprinting } \\
\text { analysis }\end{array}$ & NS & 22 & NS & 176 & 240 & 200 & $\begin{array}{c}\text { Micrococcus } \\
\text { Staphylococcus }\end{array}$ & 44 & 10 & 75 & $\begin{array}{l}\text { Aspergillus } \\
\text { Cladosporium } \\
\text { Penicillium }\end{array}$ & {$[18]$} \\
\hline Office & $\begin{array}{l}\text { SAS Super } 90 \\
\text { Impactor }\end{array}$ & Cultivation & 9,15 & NS & NS & 414 & ND & ND & ND & ND & 235 & 805 & $\begin{array}{c}\text { Cladosporium } \\
\text { Hyalodendron } \\
\text { Penicillium }\end{array}$ & [124] \\
\hline $\begin{array}{l}\text { Residence } \\
\text { (apartment) }\end{array}$ & $\begin{array}{l}\text { Six stage Andersen } \\
\text { sampler }\end{array}$ & Cultivation & 6,15 & $17-27$ & $35-85$ & NA & 0 & 2039 & $\begin{array}{c}\text { Aeromonas } \\
\text { Bacillus } \\
\text { Kocuria } \\
\text { Micrococcus } \\
\text { Nocardia } \\
\text { Pseudomonas } \\
\text { Staphylococcus }\end{array}$ & NA & 0 & 896 & $\begin{array}{l}\text { Aspergillus } \\
\text { Penicillium }\end{array}$ & [115] \\
\hline Residence & $\begin{array}{l}\text { 6-stage Andersen } \\
\text { sampler, } \\
\text { gravitational } \\
\text { sampler, } \\
\text { RCS plus } \\
\text { aeroscope }\end{array}$ & Cultivation & NS & NS & NS & NA & 88 & 4751 & $\begin{array}{l}\text { Aeromonas } \\
\text { Bacillus } \\
\text { Kocuria } \\
\text { Micrococcus } \\
\text { Nocardia } \\
\text { Pseudomonas } \\
\text { Staphylococcus }\end{array}$ & NA & 2 & 16968 & $\begin{array}{c}\text { Aspergillus } \\
\text { Penicillium } \\
\text { yeasts }\end{array}$ & [114] \\
\hline Residence & $\begin{array}{l}\text { Reuter centrifugal } \\
\text { air sampler }\end{array}$ & Cultivation & 15 & NS & NS & ND & ND & $\mathrm{ND}$ & NA & 1133 & 463 & 3125 & $\begin{array}{c}\text { Alternaria } \\
\text { Cladosporium } \\
\text { Curvularia }\end{array}$ & [6] \\
\hline Residence & $\begin{array}{l}\text { Slit-to-agar single } \\
\text { stage impactor }\end{array}$ & $\begin{array}{l}\text { Microscopy, } \\
\text { Cultivation }\end{array}$ & 6,13 & NS & NS & ND & ND & ND & NA & & & 12640 & $\begin{array}{l}\text { Aspergillus } \\
\text { Cladosporium } \\
\text { Penicillium } \\
\text { Rhizopus }\end{array}$ & [124] \\
\hline $\begin{array}{l}\text { Residence } \\
\text { (high rise } \\
\text { apartments) }\end{array}$ & NS & NS & NS & NS & NS & ND & 10 & 103 & ND & ND & 10 & 103 & $\begin{array}{c}\text { Alternaria } \\
\text { Aspergillus } \\
\text { Cladosporium } \\
\text { Penicillium }\end{array}$ & [122] \\
\hline Residence & MAS-100 & Cultivation & 3,6 & NS & NS & ND & $\mathrm{ND}$ & $\mathrm{ND}$ & NA & 250 & 310 & 1700 & $\begin{array}{l}\text { Aspergillus } \\
\text { Cladosporium } \\
\text { Penicillium }\end{array}$ & [133] \\
\hline Residence & $\begin{array}{c}\text { Six stage Andersen } \\
\text { sampler }\end{array}$ & Cultivation & 6,7 & 22 & 47 & ND & 1557 & 5036 & ND & ND & 925 & 2124 & ND & [16] \\
\hline $\begin{array}{c}\text { School } \\
\text { (classroom) }\end{array}$ & $\begin{array}{c}\text { Andersen } \\
\text { sampler }\end{array}$ & Cultivation & NS & NS & NS & 782 & $\mathrm{ND}$ & ND & ND & 811 & ND & ND & $\begin{array}{l}\text { Aspergillus } \\
\text { Cladosporium } \\
\text { Penicillium } \\
\text { yeasts }\end{array}$ & [139] \\
\hline $\begin{array}{c}\text { School } \\
\text { (classroom) }\end{array}$ & $\begin{array}{l}\text { Andersen } \\
\text { sampler }\end{array}$ & Cultivation & 15 & NS & NS & ND & 65 & 425 & $\begin{array}{c}\text { Bacillus } \\
\text { Corynebacterium } \\
\text { Micrococcus } \\
\text { Staphylococcus }\end{array}$ & ND & ND & ND & ND & [25] \\
\hline $\begin{array}{c}\text { School } \\
\text { (classroom) }\end{array}$ & $\begin{array}{l}\text { Andersen } \\
\text { sampler }\end{array}$ & Cultivation & 6,15 & $11-21$ & $17-40$ & 1002 & 269 & 1621 & ND & 415 & 324 & 616 & $\begin{array}{c}\text { Alternaria } \\
\text { Aspergillus } \\
\text { Cladosporium } \\
\text { Penicillium }\end{array}$ & [148] \\
\hline
\end{tabular}


Table 1. count......

\begin{tabular}{|c|c|c|c|c|c|c|c|c|c|c|c|c|c|c|}
\hline \multirow[t]{2}{*}{ Location } & \multirow[t]{2}{*}{ SM } & \multirow[t]{2}{*}{ ID } & \multirow[t]{2}{*}{ GM } & \multirow{2}{*}{$\begin{array}{l}\text { Temp } \\
\left({ }^{\circ} \mathrm{C}\right)\end{array}$} & \multirow{2}{*}{$\begin{array}{l}\mathrm{RH} \\
(\%)\end{array}$} & \multicolumn{4}{|c|}{ Bacterial Counts (cfu/m³) } & \multicolumn{4}{|c|}{ Fungal Counts $\left(\mathbf{c f u} / \mathbf{m}^{3}\right)$} & \multirow[b]{2}{*}{ Ref. } \\
\hline & & & & & & Ave & Min & Max & Dominant Genus & Ave & Min & $\operatorname{Max}$ & Dominant Genus & \\
\hline School & $\begin{array}{c}\text { Petri plate } \\
\text { gravitational }\end{array}$ & Cultivation & $2,6,7,8$ & 28 & 65 & 259 & ND & ND & $\begin{array}{l}\text { Corynebacterium } \\
\text { Pseudomonas } \\
\text { Staphylococcus }\end{array}$ & 371 & $\mathrm{ND}$ & ND & $\begin{array}{l}\text { Aspergillus } \\
\text { Penicillium }\end{array}$ & [135] \\
\hline $\begin{array}{c}\text { School } \\
\text { (classroom) }\end{array}$ & Air-O-cell & Microscopy & ND & $20-24$ & $23-57$ & ND & $\mathrm{ND}$ & ND & NA & 505 & 0 & 6370 & $\begin{array}{c}\text { Alternaria } \\
\text { Aspergillus } \\
\text { Bipolaris } \\
\text { Cladosporium } \\
\text { Penicillium }\end{array}$ & [134] \\
\hline $\begin{array}{c}\text { School } \\
\text { (university) }\end{array}$ & $\begin{array}{l}\text { Gravitational } \\
\text { sedimentation }\end{array}$ & $\begin{array}{l}\text { Cultivation, } \\
\text { Microscopy }\end{array}$ & 2,16 & NS & NS & ND & 390 & 630 & $\begin{array}{c}\text { Micrococcus } \\
\text { Staphylococcus }\end{array}$ & & 330 & 520 & $\begin{array}{l}\text { Aspergillus } \\
\text { Cladosporium } \\
\text { Penicillium }\end{array}$ & [137] \\
\hline $\begin{array}{c}\text { School } \\
\text { (atrium) }\end{array}$ & MAS-100eco & cultivation & 6 & $22-26$ & $33-44$ & 562 & 290 & 1270 & ND & 213 & 70 & 615 & ND & {$[56]$} \\
\hline $\begin{array}{c}\text { School } \\
\text { (university) }\end{array}$ & $\begin{array}{l}\text { Burkard single } \\
\text { stage sampler }\end{array}$ & $\begin{array}{c}\text { Identification } \\
\text { kit }\end{array}$ & 10 & NS & NS & 225 & ND & ND & $\begin{array}{c}\text { Bacillus } \\
\text { Flavobacterium } \\
\text { Micrococcus } \\
\text { Neisseria } \\
\text { Staphylococcus }\end{array}$ & ND & $\mathrm{ND}$ & ND & ND & [120] \\
\hline $\begin{array}{c}\text { School } \\
\text { (classroom) }\end{array}$ & $\begin{array}{l}\text { Andersen } \\
\text { sampler }\end{array}$ & VITEK32 & $10,13,14$ & $11-28$ & $15-64$ & 633 & 62 & 1696 & $\begin{array}{c}\text { Bacillus } \\
\text { Micrococcus } \\
\text { Staphylococcus }\end{array}$ & 100 & $\mathrm{BD}$ & 574 & $\begin{array}{l}\text { Aspergillus } \\
\text { Cadida } \\
\text { Penicillium } \\
\text { Rhizopus }\end{array}$ & [111] \\
\hline $\begin{array}{c}\text { School } \\
\text { (classroom) }\end{array}$ & Impinger & NS & ND & $19-21$ & $52-61$ & ND & 480 & 1634 & ND & ND & 100 & 660 & ND & [118] \\
\hline $\begin{array}{c}\text { School } \\
\text { (child care) }\end{array}$ & $\begin{array}{l}\text { Gravitational } \\
\text { sedimentation }\end{array}$ & $\begin{array}{l}\text { Cultivation, } \\
\text { Microscopy }\end{array}$ & 6,8 & 23 & 70 & ND & $\mathrm{ND}$ & ND & ND & ND & $\mathrm{ND}$ & ND & $\begin{array}{c}\text { Alternaria } \\
\text { Aspergillus } \\
\text { Cladosporium } \\
\text { Penicillium }\end{array}$ & [136] \\
\hline $\begin{array}{c}\text { School } \\
\text { (university) }\end{array}$ & $\begin{array}{l}\text { Settle plate } \\
\text { method }\end{array}$ & Cultivation & 7,13 & $24-25$ & $50-60$ & ND & $\mathrm{ND}$ & ND & $\begin{array}{c}\text { Bacillus } \\
\text { Staphylococcus } \\
\text { Actinomyces }\end{array}$ & ND & $\mathrm{ND}$ & $\mathrm{ND}$ & $\begin{array}{c}\text { Aspergillus } \\
\text { Cladosporium } \\
\text { Mucor }\end{array}$ & [117] \\
\hline School & MAS-100 & Cultivation & $2,6,9$ & NS & NS & ND & $\mathrm{ND}$ & ND & ND & ND & $\mathrm{ND}$ & ND & $\begin{array}{c}\text { Alternaria } \\
\text { Aspergillus } \\
\text { Cladosporium } \\
\text { Penicillium }\end{array}$ & [138] \\
\hline $\begin{array}{c}\text { School } \\
\text { (child care) }\end{array}$ & $\begin{array}{l}\text { Gravitational } \\
\text { sedimentation }\end{array}$ & $\begin{array}{l}\text { Cultivation, } \\
\text { Microscopy }\end{array}$ & 1 & 24 & 60 & 9 & 26 & ND & $\begin{array}{c}\text { Bacillus } \\
\text { Corynebacterium } \\
\text { Staphylococcus } \\
\text { Streptococcus }\end{array}$ & $\mathrm{ND}$ & $\mathrm{ND}$ & $\mathrm{ND}$ & ND & [119] \\
\hline
\end{tabular}

various environments [68, 72-74]. It is used to copy and amplify many million-fold specific regions (typically $<1000$ bases) of the genome, providing enough for analyses [1]. This method is very rapid compared to that with culture techniques and is sensitive enough for the detection of specific microorganisms which are slow growing and difficult to culture. Mainly outdoor microorganisms have been investigated using this method [75-77]. The conventional PCR assay has been applied to analyse air samples for the presence of airborne mycobacteria [78] and fungi commonly associated with adverse health effects [79]. PCR allows the detection and identification of non-culturable airborne microorganisms; it does not allow distinguishing between non-viable and viable microorganisms [80]. Currently, the real-time PCR (RT-PCR) is evolving into a promising tool capable of reproducible and accurate measurements of total microorganism concentrations in environmental samples. The advan- tage of RT-PCR is the capacity of rapid sample quantification as well as species-specific identification [81]. A recent study has demonstrated that viable Legionella pneumophila can be efficiently sampled by the AGI-30 and BioSampler and successfully quantified by with quantitative PCR [82]. As examples, real-time quantitative PCR to determine airborne bacterial loads or - more specifically - Salmonella in poultry houses was only applied recently $[83,84]$.

ATP-bioluminescence - ATP is the most important biological fuel in living organisms. An assay using ATP (adenosine triphosphate), which plays a central role as an intermediate carrier of chemical energy linking the catabolism and biosynthesis within microbial cells, has long been recognized as "the most convenient and reliable method for estimating the total microbial biomass in most environmental samples" [85-87]. ATP bioluminescence is based on a light generating 
reaction with luciferin and firefly luciferase. Since the light emitted from the reaction is proportional to the ATP concentration contained in the total biological contaminants, hygiene monitoring techniques using the ATP bioluminescence have been used to quickly access and monitor microbial contamination on surfaces, such as in food industries [88]. The method is fast, robust easy to perform, affordable and detects both cultivable and uncultivable organisms [89]. Using an aerosol condensation system in combination with an ATPbioluminescence transducer system, a biosensor has been developed to detect ATP from aerosols in real-time and to determine the existence of airborne microbes within $10 \mathrm{~min}$ [90]. The ATP bioluminescence method has also been applied to characterize the performance of bioaerosol sampling devices [91]. Detecting ATP originating in air could thus be an important method for detecting living organisms like airborne pathogens.

Spectroscopic techniques such as matrix assisted laser desorption/ionization time of flight - mass spectrometry (MALDI-TOF-MS) or Raman-spectroscopy have been recently introduced for the analysis of bioaerosols. However, some of them are still depending on cultivation prior to investigation.

Matrix assisted laser desorption/ionization time of flight mass spectrometry - MALDI-TOF mass spectra can be used for the identification microorganisms such as bacteria or fungi. A microbial is transferred from a nutrient plate directly onto the sample target. Spectra generated are analyzed by dedicated software and compared with stored known profiles. Species diagnosis by this procedure is much faster, more accurate, and cheaper than up-to-now standard procedures based on immunological or biochemical tests. In combination with an impactor sampler, bioaerosols directly deposited on a target have been analysed [92]. Using instrumental improvements it is even possible to obtain a mass spectrum of a single airborne particle allowing on-line measurements and analysis without the need of prior cultivation [93].

Raman spectroscopy - Identification of a single bacterial cell and the differentiation between spores and vegetative growth states was possible using micro-Raman spectroscopy [94]. Raman spectroscopy (together with infrared spectroscopy) is based on vibrations between the chemical bonds of the atoms making up the material representing, therefore, the chemical composition of a cell and resulting in a typical vibrational "fingerprint".

Laser-induced fluorescence - Fluorescence spectra of bacteria obtained after excitation by laser light can result in a differentiation of the organisms. Air samples were collected by impaction, subsequently cultivated and classified by the fluorescence signals which were correlated to morphology, Gram staining or family [95]. A differentiation on the species level was not possible.

\section{COMPOSITION OF BIOAEROSOLS}

Bacteria - Typical and most important bacterial strains found in an indoor atmosphere are representatives of the genera Bacillus, Micrococcus, Kocuria and Staphylococcus. Bacilli have the ability to form spores which are character- ized by their resistance to harsh environmental conditions such as UV radiation, desiccation, lack of nutrients, or extreme temperatures. These metabolic capabilities facilitate the distribution and survival. Micrococcus and Kocuria are able to produce colored (pink, yellow, orange, and red) pigments, which is typical for a large portion of airborne microorganisms [96]. It is assumed that these pigments act as "sun screen" for the organisms to protect them from UV radiation. However, pigments are also formed during long term storage of bacterial cultures at $4^{\circ} \mathrm{C}$ in the dark (Brandl, unpublished observation), what assumes a function as "anti-freezing agent". In addition, there are a few reports on the relationship between pigmentation and pathogenicity, virulescence, and resistance to antibiotics [97, 98].

Several studies have reported that exposure to large concentrations of airborne microbes is often associated with asthma and rhinitis [99], hypersensitivity pneumonitis [100] and sick building syndrome [101]. In addition, exposure to microbes has also been associated with a number of other health effects, including infections [102]. Among the various indoor environment various bacteria such as Bacillus sp., Streptomyces albus, Pantoea agglomerans, Pseudomonas chlororaphis, Arthrobacter globiformis, Thermoactinomycetes vulgaris, and Corynebacterium sp. were identified which were known to have allergenic or immunotoxic effects on human health (Table 1), [103-105]. Results have shown that the occurrence of distinct and reproducible short term dynamics (on a time scale of minutes) of total particles and bioaerosols related to periods of anthropogenic activity (presence/absence of people) in the University hallway, i.e. when lectures are held in lecture rooms and the intermissions in between [64]. In general when monitoring air quality of indoor environments for the occurrence of both biological and total particles, these short-term temporal dynamics need to be considered. The predominant genera of airborne bacteria in a general hospital were Staphylococcus, Bacillus, Micrococcus, Corynebacterium [76, 106-108]. The bacterial counts ranged from 35 to $728 \mathrm{cfu} / \mathrm{m}^{3}$. The principal factors to affect the level of airborne microorganisms might be not cleanliness of hospital but the activity of people, organic materials derived from the outdoors and ventilation efficiency applied to hospital. Exposure of the immunecompromised people like patients to airborne bacteria and fungi distributed in the air of general hospital can be potentially associated with respiratory diseases although most of airborne microorganisms identified in general hospital do not have pathogenicity [108].

Airborne microbes were detected in museums by various workers and bacterial counts ranged from 545 to $883 \mathrm{cfu} / \mathrm{m}^{3}$ $[109,110]$. The five dominant groups include Staphylococcus, Arthrobacter, Bacillus, Pseudomonas and Micrococcus. The museum environment is of critical importance for the preventive conversation (for the storage and display of objects) and for the visitors health. Due to a correctly operated and maintained air-conditioning systems and limited number of visitors, good air quality of the studied storerooms and low levels of microbial contamination of museum collections were observed [109]. Considering the bacterial species present in office buildings, predominance of Micrococcus and Staphylococcus genera is seen, which could be due to the human presence $[18,111,112]$. The bacterial counts ranged 
from 900 to $3100 \mathrm{cfu} / \mathrm{m}^{3}[11,113]$. In residential appartements the dominant bacterial genus were Aeromonas, Bacillus, Kocuria, Micrococcus, Nocardia, Pseudomonas and Staphylococcus. The bacterial counts ranged from 88 to 4750 $\mathrm{cfu} / \mathrm{m}^{3}[114,115]$. In schools, predominance of Bacillus, Corynebacterium, Micrococcus, Staphylococcus were seen and bacterial count was high as $1696 \mathrm{cfu} / \mathrm{m}^{3}[111,116-120]$.

Fungi - Fungal strains which are proportionally of importance in indoor air samples are comprised of the genera $\mathrm{Al}$ ternaria, Aspergillus, Cladosporium, and Penicillium [121126]. All fungal strains are able to form spores which are resistant to changing environmental conditions. In all the studies surveyed for this review, fungi are always characterized using culture dependent techniques followed by standard identification protocols (Table 1). For individual fungi, the threshold concentrations for evoking allergic symptoms have been estimated as 100 Alternaria spores per cubic meter air [127], while Aspergillus sp. spore concentrations above $50 \mathrm{cfu}$ per $\mathrm{m}^{3}$ have been potentially associated with a higher prevalence of sick building syndrome [128]. Evidence from both epidemiological and experimental studies supports the fact that these are highly allergenic fungi. They are known to cause allergic diseases of the respiratory system such as bronchial asthma and allergic rhinitis [129-131]. High fungal concentration was observed in hospital environment ranging from $3419-7701 \mathrm{cfu} / \mathrm{m}^{3}$ [77]. In offices the range was much lower from 106 to $1113 \mathrm{cfu} / \mathrm{m}^{3}[18,75,111$, 132]. Higher mould concentrations $\left(463-3125 \mathrm{cfu} / \mathrm{m}^{3}\right)$ were observed in dwelling places since these environments may promote mould growth due to high relative humidity and the existence of potential substrates $[6,16,133]$. In schools the fungal count ranged from 70 to $6370 \mathrm{cfu} / \mathrm{m}^{3}[111,118,134-$ 139]. Fungal growth in indoor air depends on mainly on moisture and available carbon sources. Therefore, most important strategies for the reduction or the elimination of fungal growth is controlling moisture present and reducing indoor organic contaminants [77]. Mechanized ventilation, forced air-heating systems, dehumidifiers, air filters, and air conditioners reduce indoor fungal count [140]. The design, construction, and maintenance of building envelopes is crucial for the prevention of excess moisture and subsequent fungal growth [141].

\section{MAXIMUM ACCEPTABLE LEVELS OF BACTERIAL AND FUNGAL BIOAEROSOLS}

There is no uniform international standard available on levels and acceptable maximum bioaerosol loads, what has been pointed out already earlier [142]. Even terms and wording is different in different countries and include e.g., "threshold limit value, TLV" [143-144], "acceptable airborne bacteria levels" [145], "guideline value" [116, 146, 147, 148], "orientation value" [149], "acceptable maximum value, AMV [118], "maximum acceptable value" [150], "maximum allowable concentration" [151], "contamination indicator" [152].

The American Conference of Governmental Industrial Hygienists (ACGIH) is stating that "a general TLV for culturable or countable bioaerosol concentrations is not scientifically supported" due to the lack of data describing exposure-response relationships [144]. Additionally, ACGIH is stressing that "bioaerosols in occupational settings are gen- erally complex mixtures of many different microbial, animal and plant particles". At the moment, there is no uniform standardized method available for the collection and the analysis of bacterial and fungal biaerosols, which makes the establishment of exposure limits difficult [144, 149]. Attempts have been made to model and predict acceptable airborne bacteria levels in indoor environments such as e.g., air-conditioned spaces including airborne bacterial counts $\left(\mathrm{cfu} \mathrm{m}^{-3}\right)$, temperature and relative humidity [145].

Published values for acceptable bacterial and fungal bioaerosol concentrations vary from country to country and are exemplarily shown in Table 2 [153-158]. Values are related in some cases to specific indoor sampling locations (Chinese guidelines, guidelines of the European Commission). In addition, guideline values tolerated have been established in relation to specified groups of microorganisms such as Gram-negative bacteria or a specific microbial strain such as e.g., Penicillium canescens (Russian and Swiss Guidelines). However, neither air sampling techniques nor identification and cultivation methods have been internationally standardized reducing, therefore, the comparability of data.

\section{CONCLUSION}

Exposure to bioaerosols has already been associated with a wide range of health effects such as e.g., infectious diseases, acute toxic effects or allergies. Owing to the ubiquitous presence of airborne microbes in nature, they are essentially present in most enclosed environments $[159,160]$. With every breath we inhale approximately 0.5 litres of air. By making 15 breaths per minute, $10 \mathrm{~m}^{3}$ of air are transferred to our lungs during the course of one day. It can be assumed that $1000 \mathrm{cfu}$ (colony forming units, i.e. microbial (bacterial or fungal) cells able to growth on solid nutrient media) are present per $\mathrm{m}^{3}$. However, this represents only a fraction of approximately $1 \%$ of all microorganisms present, a value typically found by a series studies in soil, aquatic sediments, or water [e.g., 162, 163]; and also applicable for air samples. This low percentage is due to our limited abilities to mimic natural nutrient requirements and other environmental parameters needed for cultivation.. In total, therefore, we inhale approximately $10^{6}$ microbial cells per day.

As observed in several studies [159], the high bacterial count within buildings compared to that observed outdoor could be associated with various internal sources, including human activities. A programmed and periodical cleaning operation and maintenance activities of various indoor environment should be organised as a preventive measure. Increasing the ventilation rate by means of mechanical or natural systems can play a role in improving the indoor air quality. High fungal concentrations in various indoor environments and the presence of allergenic genera point out a potential health risk such as respiratory diseases. Combining the indoor microbial load data with data from studies focusing on health effects caused by inhalation of specific airborne microorganisms will allow the evaluation of various risks to which inhabitants are exposed.

\section{ACKNOWLEDGEMENT}

The authors thank the Biosafety Office of the Canton of Zurich (Zurich, Switzerland) for support. 
Table 2. "Guideline Values" of Bacterial and Fungal Bioaerosols (Bacteria, Fungi) in Different Selected Countries. "for a Mixture of Species; ${ }^{b}$ Depending on Location Such as e.g. Hotels, Movie Theatres, Libraries, Museums; ${ }^{c}$ NS: not Specified, but "no

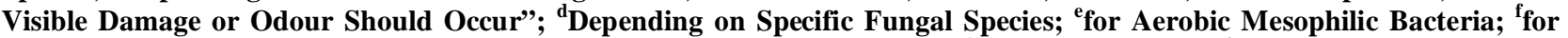
Gram-Negative Bacteria; ${ }^{\mathrm{g}}$ TLV (Threshold Limit Value) is not Supportable; ${ }^{\mathrm{h}}$ for Private Homes; ${ }^{\text {i }}$ (or Non-Industrial Indoor Locations

\begin{tabular}{|c|c|c|c|c|}
\hline \multirow[t]{2}{*}{ Country, Organization } & \multicolumn{3}{|c|}{ Number of Culturable Organisms as Colony Forming Units (cfu $\mathrm{m}^{-3}$ ) } & \multirow[t]{2}{*}{ References } \\
\hline & Bacteria & Fungi & Total Bioaerosols (Bacteria + Fungi) & \\
\hline Brazil & & 750 & & {$[150,161]$} \\
\hline Canada & & $150^{\mathrm{a}}$ & & [116] \\
\hline China & 2500 to $7000^{\mathrm{b}}$ & & & [115] \\
\hline Finland & 4500 & & & [156] \\
\hline Germany & 10000 & 10000 & & {$[153,154]$} \\
\hline Korea & & & 800 & [148] \\
\hline Portugal & & 500 & & [118] \\
\hline Netherlands & 10000 & & 10000 & [157] \\
\hline Norway & & $\mathrm{NS}^{\mathrm{c}}$ & & [146] \\
\hline Russia & & 2000 to $10000^{\mathrm{d}}$ & & [151] \\
\hline Switzerland & $\begin{array}{c}10000^{\mathrm{e}} \\
1000^{\mathrm{f}}\end{array}$ & 1000 & & {$[149,158]$} \\
\hline USA & $--^{g}$ & $\begin{array}{c}--{ }^{g} \\
1000\end{array}$ & $--^{g}$ & {$[144,152]$} \\
\hline WHO & 500 & & & {$[147,155]$} \\
\hline European Union & $\begin{array}{r}10000^{\mathrm{h}} \\
2000^{\mathrm{i}}\end{array}$ & $\begin{array}{c}10000^{\mathrm{h}} \\
2000^{\mathrm{i}}\end{array}$ & & [143] \\
\hline
\end{tabular}

\section{ABBREVIATIONS}

ACGIH

AMV

ATP

CFU

DAPI

DG-18 Agar

ELISA

EMA-qPCR

ESP

FISH

tion

LIF

MALIDI-TOF-MS

MAS

MEA
$=$ American conference of governmental industrial hygienists

$=$ Acceptable maximum value

$=$ Adenosine triphosphate

$=$ Colony forming units

$=\quad 4,6$ diamidino-2-phenylindol

$=$ Dichloran glycerol-18 agar

$=$ Enzyme linked immunosorbent assay

$=$ Ethidium monoazide with quantitative polymerase chain reaction

$=$ Electrostatic precipitators

$=\quad$ Fluorescence in situ hybridisa-

$=$ Laser induced fluorescence

$=$ Matrix assisted laser desorption/ionization time of flight mass spectrometry

$=$ Microbiological air sampler

$=$ Malt extract agar
NA

PCR

PM2.5

PVC

RIA

RT-PCR

TLV

TSA

WGA

$=$ Nutrient agar

$=$ Polymerase chain reaction

$=\quad$ Particulate matter $<2.5 \mu \mathrm{m}$

$=$ Polyvinylchloride

$=$ Radio immunoassay

$=$ Real time polymerase chain reaction

$=$ Threshold limit value

$=$ Tryptic soy agar

$=$ Wheat germ agglutinin

\section{REFERENCES}

[1] Georgakopoulos DG, Despres V, Froehlich-Nowoisky J, et al. Microbiology and atmospheric processes: biological, physical and chemical characterization of aerosol particles. Biogeosciences 2009; 6: 721-37.

[2] Heikkienen MSA, Hjelmroos-Koski MK, Haggblom MM, Macher JM. Bioaerosols. In: Ruzer LS, Harley NH, Eds. Aerosols Handbook. Boca Raton: CRC Press 2005; pp. 291-342.

[3] Jaenicke R. Abundance of cellular material and proteins in the atmosphere. Science 2005; 308: 73.

[4] Pillai SD, Ricke SC. Bioaerosols from municipal and animal wastes: background and contemporary issues. Can J Microbiol 2002; 48: 681-96.

[5] Pope CA, Dockery DW, Schwartz J. Review of epidemiological evidence of health effects of particulate air pollution. Inhal Toxicol 1995; 7: 1-18. 
[6] Hargreaves M, Parappukkaran S, Morawska L, Hitchins J, Congrong $\mathrm{H}$, Gilbert D. A pilot investigation into associations between indoor airborne fungal and non-biological particle concentrations in residential houses in Brisbane. Sci Total Environ 2003; 312: 89-101.

[7] Stetzenbach LD, Buttner MP, Cruz P. Detection and enumeration of airborne contaminants. Curr Biotechnol 2004; 15: 170-4.

[8] Camuffo D, Brimblecombe P, van Grieken R, et al. Indoor air quality at the Correr Museum, Venice, Italy. Sci Total Environ 1999; 236: 135-52.

[9] Stetzenbach LD. Introduction to aerobiology. In: Manual of Environmental Microbiology. Washington DC: ASM Press 1997; pp. 619-28.

[10] Cox CS, Wathes CM. Bioaerosols handbook. New York: Lewis Publishers, 1995.

[11] Kalogerakis N, Paschali D, Lekaditis V, Pantidou A, Eleftheriadis $\mathrm{K}$, Lazaridis M. Indoor air quality - bioaerosol measurements in domestic and office premises. J Aerosol Sci 2005; 36: 751-61.

[12] Foarde K, Dulaney P, Cole, E., VanOsdel, D, Ensor D, Chang J. Assessment of fungal growth on ceiling tiles under environmentally characterized conditions. In Kalliokoski P, Jantunen M, Seppänen O, Eds. Proc. Indoor Air 1993; 4: 357-62.

[13] Pasanen AL, Kasane JP, Rautiala S, et al. Fungal growth and survival in building materials under fluctuating moisture and temperature conditions. Int Biodeter Biodegrad 2000; 46: 117-27.

[14] Kulmala M, Asmi A, Pirjola L. Indoor air aerosol model: The effect of outdoor air, filtration and ventilation on indoor concentrations. Atmos Environ 1999; 33: 2133-44.

[15] American Conference of Governmental Industrial Hygienists (ACGIH). Bioaerosols: Assessment and control. Cincinnati, American Conference of Governmental Industrial Hygienists, 1999.

[16] Nasir ZA, Colbeck I. Assessment of bacterial and fungal aerosol in different residential settings. Water Air Soil Pollut 2010; 211: 36777.

[17] Nevälainen A, Seuri M. Of microbes and men. Indoor Air 2005; 15: $58-64$

[18] Bonetta S, Bonetta S, Mosso S, Sampo S, Carraro E. Assessment of microbiological indoor air quality in an Italian office building equipped with an HVAC system. Environ Monit Assess 2010; 161: 473-83.

[19] Kim, KY, Kim CN. Airborne microbiological characteristics in public building of Korea. Build Environ 2007; 42: 2188-96.

[20] Huttunen K, Rintala H, Hirvonen MR, et al. Indoor air particles and bioaersols before and after renovation of moisture-damaged buildings: the effect on biological activity and microbial flora. Environ Res 2008; 107: 291-8.

[21] Stanley NJ, Kuehn TH, Kim SW, et al. Background culturable bacteria aerosol in two large public buildings using HVAC filters as long term, passive, high-volume air samplers. J Environ Monit 2008; 10: 474-81

[22] Srikanth P, Sudharsanam S, Steinberg R. Bioaerosols in indoor environment: Composition, health effects and analysis. Indian $\mathbf{J}$ Med Microbiol 2008; 26: 302-12.

[23] Loftness V, Hakkinen B, Adnan O, Nevälainen A. Elements that contribute to healthy building design. Environ Health Perspect 2007; 115: 965-70.

[24] Seppaenen O, Fisk WJ. Association of ventilation system type with SBS symptoms in office workers. Indoor Air 2002; 12: 98-112.

[25] Bartlett KH, Kennedy SM, Brauer M, van Netten C, Dill B. Evaluation and determinants of airborne bacterial concentrations in school classrooms. J Occup Environ Hyg 2004; 1: 639-47.

[26] Green CF, Scarpino PV, Gibbs SG. Assessment and modelling of indoor fungal and bacterial bioaerosol concentrations. Aerobiologia 2003; 19: 159-69.

[27] Zollinger M, Krebs W, Brandl H. Bioaerosols formation during grape stemming and crushing. Sci Total Environ 2006; 363: 253-9.

[28] Perkins WA. The Rotorod sampler. Second semi-annual report. Aerosol lab, Department of Chemical Engineering: Stanford University, 1957; vol. 186: pp. 66-9.

[29] Harrington JB, Gill GC, Warr BR. High efficiency pollen samplers for use in clinical allergy. J Allergy 1959; 30: 357-75.

[30] Feller W. An introduction to the probability theory and its application. New York: Wiley 1950.

[31] Andersen AA. New sampler for the collection, sizing and enumeration of viable airborne particles. J Bacteriol 1958; 76: 357-75.
[32] Casewell MW, Fermie PG, Thomas C, Simmons NA. Bacterial air counts obtained with a centrifugal (RCS) sampler and a slit sampler - the influence of aerosols. J Hosp Infect 1984; 5: 76-82.

[33] Brandl H, Bachofen, R, Bischoff M. Generation of bioaerosols during manual mail unpacking and sorting. J Appl Microbiol 2005; 99:1099-1107

[34] Terzieva S, Donnelly J, Ulevicius V, et al. Comparison of methods for detection and enumeration of airborne microorganisms collected by liquid impingement. Appl Environ Microbiol 1996; 62: 2264-72.

[35] Lin WH, Li CS. Evaluation of impingement and filtration methods for yeast bioaerosol sampling. Aerosol Sci Technol 1999; 30:119 126.

[36] May KR, Harper J. The efficiency of various liquid impinger samplers in bacterial aerosols. Br J Ind Med 1957; 14: 287-97.

[37] Ding PH, Wang CS. Effect of sampling time on the total recovery of AGI-30 impingers for E. coli aerosols. Aerosol Air Qual Res 2001; 1: 31-6.

[38] Ogden EC, Lewis DM, Haines JH. Manual for sampling airborne pollen. New York: Hafner Press 1974

[39] Hirst JM. An automatic volumetric trap. Ann Appl Biol 1952; 39: 73-8

[40] British Aerobiology Federation. A guide to trapping and counting, Larkfield, Aylesford, Kent, UK, Kimberley Clark Ltd., 1995.

[41] Yao MS, Mainelis G. Analysis of portable impactor performance for enumeration of viable bioaerosols. J Occup Environ Hyg 2007; 4: 514-24.

[42] Kenny LC, Stancliffe JD, Crook B, et al. The adaptation of existing personal inhalable aerosol samplers for bioaerosol sampling. Am Ind Hyg Assoc J 1998; 59: 831-41.

[43] Yao M, Mainelis G. Effect of physical and biological parameters on enumeration of bioaerosols by portable microbial impactors. Aerosol Sci 2006; 37: 1467-83.

[44] Yao MS, Mainelis G. Investigation of cut-off sizes and collection efficiencies of portable microbial samplers. Aerosol Sci Technol 2006; 40: 595-606.

[45] Yao MS, Mainelis G. Use of portable microbial samplers for estimating inhalation exposure to viable biological agents. J Exposure Sci Environ Epidemiol 2007; 17: 31-8.

[46] Mainelis G, Willeke K, Adhikari A, et al. Design and collection efficiency of a new electrostatic precipitator for bioaerosol collection. Aerosol Sci Technol 2002; 36: 1073-85.

[47] Mainelis G, Grinshpun SA, Willeke K, et al. Collection of airborne microorganisms by electrostatic precipitation. Aerosol Sci Technol 1999; 30: 127-44.

[48] Mainelis G, Adhikari A, Willeke K, Lee SA, Reponen T, Grinshpun SA. Collection of airborne microorganisms by a new electrostatic precipitator. J Aerosol Sci 2002; 33: 1417-32.

[49] Rule AM, Kesavan J, Schwab KJ, Buckley TJ. Application of flow cytometry for the assessment of preservation and recovery efficiency of bioaerosol samplers spiked with Pantoea agglomerans. Environ Sci Technol 2007; 41: 2467-72.

[50] Willeke K, Lin XJ, Grishpun SA. Improved aerosol collection by combined impaction and centrifugal motion. Aerosol Sci Technol 1998; 28: 439-56

[51] Jensen PA, Todd WF, Davis GN, Scarpino PV. Evaluation of 8 bioaerosol samplers challenged with aerosols of free bacteria. Am Ind Hyg Assoc J 1992; 53: 660-7.

[52] Li CS, Lin YC. Sampling performance of impactors for bacterial bioaerosols. Aerosol Sci Technol 1999; 30: 280-7.

[53] Mainelis G, Tabayoyong M. Effect of sampling time on the overall performance of the portable microbial impactors. Aerosol Sci Technol 2010; 44: 75-82.

[54] Albrecht A, Witzenberger R, Bernzen U, et al. Comparative measurements of airborne bacteria by using filtration (MD8) and impingement (AGI-30) in a composting facility [in German]. Gefahrstoffe - Reinhaltung der Luft 2005; 65: 358-62.

[55] Parat S, Perdrix A, Mann S, Baconnier P. Contribution of particle counting in assessment of exposure to airborne microorganisms. Atmos Environ 1999; 33: 951-9.

[56] Brandl H, von Däniken A, Hitz C, Krebs W. Short term dynamic patterns of bioaerosols generation and distribution in an indoor environment. Aerobiologia 2008; 14: 203-9.

[57] Agranovski V, Ristovski Z, Blackall PJ, Morawska L. Sizeselective assessment of airborne particles in swine confinement building with the UVAPS. Atmos Environ 2004; 38: 3893-901. 
[58] Luoma M, Batterman SA. Characterization of particulate emissions from occupant activities in offices. Indoor Air 2001; 11: 35-48.

[59] Martinez KF, Rao CY, Burton NC. Exposure assessment and analysis for biological agents. Grana 2004; 43: 193-204.

[60] Cruz P, Buttner MP. Analysis of bioaerosol samples. In: Hurst CJ, Crawford RL, Garland JL, Lipson DA, Mills AL, Stezenbach LD, Eds. Manual of environmental microbiology, 3rd ed. Washington DC: ASM Press 2007; pp. 952-960.

[61] Burge HA. Bioaerosol investigations, In: Bioaerosols. Burge HA, Eds. Boca Raton, USA: CRC Press, 1995; pp. 1-23.

[62] Amann R, Ludwig W. Ribosomal RNA-targeted nucleic acid probes for studies in microbial ecology. FEMS Microbiol Rev 2000; 24: 555-65.

[63] Pernthaler J, Glöckner FO, Unterholzner S, et al. Seasonal community and population dynamics of pelagic bacteria and Archaea in a high mountain lake. Appl Envion Microbiol 1998; 64: 4299-306.

[64] Chi MC, Li CS. Fluorochrome and fluorescent in situ hybridization to monitor bioaerosols in swine buildings. Aerosol Sci Technol 2005; 39: 1101-10.

[65] Buttner MP, Willeke, K, Grinshpun SA. Sampling and analysis of airborne microorganisms In: Hurst CJ, Knudsen GR, McInerney MJ, Stetzenbach LD, Walter MV, Eds. Manual of environmental Microbiology. Washington D.C: ASM Press 1997; pp. 629-40.

[66] Gilbert Y, Duchaine C. Bioaerosols in industrial environments: a review. Can J Civil Eng 2009; 36: 1873-86.

[67] Burge HA, Pierson DL, Groves TO, Strawn KF, Mishra S.K. Dynamics of airborne fungal populations in a large office building. Curr Microbiol 2000; 40: 10-16.

[68] Gilbert Y, Veillette M, Duchaine C. Airborne bacteria and antibiotic resistance genes in hospital rooms. Aerobiologia 2010; 26: 185-94.

[69] Sharma D, Dutta BK, Singh AB. Exposure to indoor fungi in different working environments: A comparative study. Aerobiologia 2010; 26: 327-37.

[70] Lange JL, Thorne PS, Lynch N. Application of flow cytometry and fluorescent in situ hybridization for assessment of exposures to airborne bacteria. Appl Environ Microbiol 1997; 63: 1557-63.

[71] Hernlem BJ, Ravva SV. Application of flow cytometry and cell sorting to the bacterial analysis of environmental aerosol samples, J Environ Monit 2007; 9: 1317-22.

[72] Alvarez AJ, Buttner MP, Stetzenbach LD. PCR for bioaerosol monitoring: sensitivity and environmental interference. Appl Environ Microbiol 1995; 61: 3639-44.

[73] MacNeil L, Kauri T, Robertson W. Molecular techniques and their potential application in monitoring the microbiological quality of indoor air. Can J Microbiol 1995; 41: 657-65.

[74] Zeng QY, Westermark SO, Rasmuson-Lestander A, Wang XR. Detection and quantification of Wallemia sebi in aerosols by realtime PCR, conventional PCR, and cultivation. Appl Environ Microbiol 2004; 70: 7295-302.

[75] Brodie EL, DeSantis TZ, Parker JP, et al. Urban aerosols harbor diverse and dynamic bacterial populations. Proc Natl Acad Sci USA 2007; 104: 299-304

[76] Dungan RS, Leytem AB, Verwey SA, Bjorneberg DL. Assessment of bioaerosols at a concentrated dairy operation. Aerobiologia 2010; 26: 171-84.

[77] Oppliger A, Charriere N, Droz PO, Rinsoz T. Exposure to bioaerosols in poultry houses at different stages of fattening; use of realtime PCR for airborne bacterial quantification. Ann Occup Hyg 2008; 52: 405-12.

[78] Schafer MP, Martinez KF, Mathews ES. Rapid detection and determination of the aerodynamic size range of airborne mycobacteria associated with whirlpools. Appl Occup Environ Hyg 2003; 18: 4150 .

[79] Williams RH, Ward, E, McCartney HA. Methods for integrated air sampling and DNA analysis for detection of airborne fungal spores. Appl Environ Microbiol 2001; 67: 2453-9.

[80] Dungan RS, Leytem AB. Qualitative and quantitative methodologies for determination of airborne microorganisms at concentrated animal-feeding operations. World J Microbiol Biotech 2009; 25: $1505-18$

[81] Ana HR, Mainelis G, White L. Development and calibration of real-time PCR for quantification of airborne microorganisms in air samples. Atmos Environ 2006; 40: 7924-39.
[82] Chang CW, Chou FC. Assessment of bioaerosol sampling techniques for viable Legionella pneumophila by ethidium monoazide quantitative PCR. Aerosol Sci Technol 2011; 45: 343-51.

[83] Rinsoz, T, Duqunne P, Greff-Mirguet G, Oppliger A. Application of real-time PCR for total airborne bacterial assessment: Comparison with epifluorescence microscopy and culture-dependent methods. Atmos Environ 2008; 42: 6767-74.

[84] Fallschissel K, Kämpfer P, Jäckel U. Direct detection of Salmonella cells in the air of livestock stables by real -time PCR. Ann Occup Hyg 2009; 53: 859-68.

[85] Kim SY, Kim ZY, Lee S, Ko GP. Comparison of molecular and total ATP-based analytical methods with culture for the analysis of bioaerosols. Sci Total Environ 2011; 409: 1732-7.

[86] Karl DM. Cellular nucleotide measurements and applications in microbial ecology. Microbiol Rev 1980; 44: 739-96.

[87] Stewart IW, Leaver G, Futter SJ. The enumeration of aerosolized Saccharomyces cerevisiae using bioluminescent assay of total adenylates. J Aerosol Sci 1997; 28: 511-23.

[88] Tuncan EU, Martin SE. Lysostaphin lysis procedure for detection of Staphylococcus aureus by the firefly bioluminescent ATP method. Appl Environ Microbiol 1987; 53: 88-91.

[89] Velten S, Hammes F, Boller M, Egli T. Rapid and direct estimation of active biomass on granular-activated carbon through adenosine tri-phosphate (ATP) determination. Water Res 2007; 41: 1973-83.

[90] Lee SJ, Park JS, Im HT, Jung HI. A microfluidic ATP bioluminescence sensor for the detection of airborne microbes. Sens Actuators B 2008; 132: 443-8.

[91] Seshadri S, Han T, Krumins V, et al. Application of ATP bioluminescence method to characterize performance of bioaerosol sampling devices. J Aerosol Sci 2009; 40: 113-21.

[92] Kim JK, Jackson SN, Murray KK. Matrix-assisted laser desorption/ionization mass spectrometry of collected bioaerosol particles. Rapid Comm Mass Spectrosc 2005; 19: 1725-9.

[93] Kleefsman WA, Stowers MA, Verheijen PJT, Marijnissen JCM. Single particle mass spectrometry - bioaerosol analysis by MALDI -MS. Kona 2008; 26: 205-14.

[94] Cabredo S, Parra A, Saenz C, Anzano J. Bioaerosols chemometric characterization by laser-induced fluorescence: Air sample analysis. Talanta 2009; 77: 1837-42.

[95] Rösch P, Harz M, Schmitt M, et al. Chemotaxonomic identification of single bacteria by micro-Raman spectroscopy: Application to clean-room-relevant biological contaminations. Appl Environ Microbiol 2005; 71: 1626-37.

[96] Tong T, Lighthart B. Solar radiation is shown to select for pigmented bacteria in the ambient outdoor atmosphere. Photochem Photobiol 1997; 65: 103-6.

[97] Liu GY, Nizet V. Colour me bad: Microbial pigments as virulence factor. Trends Microbiol 2009; 17: 406-13.

[98] Schloss P, Allen HK, Klimowicz AK, et al. Psychrotrophic strain of Janthinobacterium lividum from a cold Alaskan soil produce prodigiosin. DNA Cell Biol 2010; 29: 533-41.

[99] Beaumont F. Clinical manifestations of pulmonary Aspergillus infections. Mycoses 1988; 31: 5-20.

[100] Siersted HC, Gravensen S. Extrinsic allergic alveolitis after exposure to the yeast Rhodotorula rubra. Allergy 1993; 48: 298-9.

[101] Dales RE, Zwanenburg H, Burnett R, Franklin CA. Respiratory health effects of home dampness and molds among Canadian children. Am J Epidemiol 1991; 134: 196-203.

[102] Ren P, Jankun TM, Leaderer BP. Comparisons of seasonal fungal prevalence in indoor and outdoor air and in housedusts of dwellings in one Northeast American county. J Exp Anal Environ Epidemiol 1999; 9: 560-8

[103] Dutkiewicz J. Bacteria, fungi and endotoxin as potential agents of occupational biohazard in a potato processing plant. Am J Ind Med 1994; 25: 43-6.

[104] Dutkiewicz J, Krysinska-Traczyk E, Skorska C, Sitkowska J, Prazmo Z, Urbanowicz B. Exposure of agricultural workers to airborne microorganisms and endotoxin handling of various vegetable products. Aerobiologia 2000; 16: 193-8.

[105] Dutkiewicz J, Krysinska-Traczyk E, Skorska C, et al. Exposure to airborne microorganisms and endotoxin in a potato processing plant. Ann Agric Environ Med 2002; 9: 225-35.

[106] Li CS, Hou PA. Bioaerosol characteristics in hospital clean rooms. Sci Total Environ 2003; 305: 169-76. 
[107] Wang CC, Fang GC, Kuo CH. Bioaerosols as contributors to poor air quality in Taichung City, Taiwan. Environ Monit Assess 2010; 166: 1-9.

[108] Kim KY, Kim CN, Kim D. Distribution characteristics of airborne bacteria and fungi in the general hospitals of Korea. Ind Health 2010; 48: 236-43

[109] Niesler A, Gorny RL, Wlazlo A, et al. Microbial contamination of storerooms at the Auschwitz-Birkenau Museum. Aerobiologia 2010; 26: 125-33.

[110] Chen YP, Cui Y, Dong JG. Variation of airborne bacteria and fungi at Emperor Qin's Terra-Cotta Museum, Xi'an, China, during the "Oct. 1" Gold Week Period of 2006. Environ Sci Pollut Res 2010; 17: 478-85.

[111] Mentese S, Arisoy M, Rad AY, Gullu G. Bacteria and fungi levels in various indoor and outdoor environments in Ankara, Turkey. Clean 2009; 37: 487-93.

[112] Tsai FC, Macher JM. Concentrations of airborne culturable bacteria in 100 large US office buildings from the BASE study. Indoor Air 2005; 15: 71-81.

[113] Zhu H, Phelan PE, Duan T, et al. Experimental study of indoor and outdoor airborne bacterial concentrations in Tempe, Arizona, USA. Aerobiologia 2003; 19: 201-11.

[114] Gorny RL, Dutkiewicz J. Bacterial and fungal aerosols in indoor environment in Central and Eastern Countries. Ann Agric Environ Med 2002; 9: 17-23.

[115] Gorny RL. Biologiczne czynniki szkodliwe: normy, zalecenia i propozycje wartości dopuszczalnych. Podstawy i Metody Oceny Środowiska Pracy 2004; 3: 17-39.

[116] Bartlett KH, Lee KS, Stephens G, Black W, Brauer M, Copes R. Evaluating indoor air quality: Test standards for bioaerosols. Report to the Workers' Compensation Board of British Columbia Research Secretariat, no. 2003; 99FS-64.

[117] Giulio MD, Grande R, Campli ED, Bartolomeo SD, Cellini L. Indoor air quality in university environments. Environ Monit Assess 2010; 170: 509-17.

[118] Pegas PN, Evtyugina MG, Alves CA, et al. Outdoor/indoor air quality in primary schools in Lisbon: a preliminary study. Quim Nova 2010; 33: 1145-9.

[119] Aydogdu H, Asan A, Otkun M. T. Indoor and outdoor airborne bacteria in child day-care centers in Edirne City (Turkey), seasonal distribution and influence of meteorological factors. Environ Monit Assess 2010; 164: 53-66.

[120] Chan DWT, Leung PHM, Tam, CSY, Jones AP. Survey of airborne bacterial genus as a university campus. Indoor Built Environ 2008; 17: 460-6.

[121] Ren P, Jankun TM, Belanger K, Bracken MB, Leaderer BP. The relation between fungal propagules in indoor air and home characteristics. Allergy 2001; 56: 419-24.

[122] Lee JH, Jo WK. Characteristics of indoor and outdoor bioaerosols at Korean high-rise apartment buildings. Environ Res 2006; 101: $11-17$.

[123] Zorman T, Jersek B. Assessment of bioaerosol concentrations in different indoor environments. Indoor Built Environ 2008; 17: 15563.

[124] Bernasconi C, Rodolfi M, Picco AM, Grisoli P, Dacarro C, Rembges D. Pyrogenic activity of air to characterize bioaerosol exposure in public buildings: a pilot study. Lett Appl Microbiol 2010; 50: 571-7.

[125] Gorny RL, Dutkiewicz J, Krysinska-Traczyk E. Size distribution of bacterial and fungal bioaerosols in indoor air. Ann Agric Environ Med 1999; 6: 105-13.

[126] Lugauskas A, Krikstaponis A, Seskauskas V. Species of conditionally pathogenic micromycetes in the air of dwellings and occupational premises. Indoor Built Environ 2003; 12: 167-77.

[127] Gravensen S, Larsen L, Gyntelberg F, Skov P. Demonstration of microorganisms and dust in schools and offices. Allergy 1986; 41: 520-5.

[128] Holmberg K. Indoor mold exposure to health effects. In: Seifert B, Esdorn H, Fischer M, Ruden H, Wegner J, Eds. Indoor Air' 87: Volatile organic compounds, combustion gases, particles and fibers, microbiological agents, Vol. 1, Berlin, Institute for Water, Soil and Air Hygiene 1987; pp. 637-42.

[129] Achatz G, Oberkofler H, Lechenauer E, et al. Molecular cloning of major and minor allergens of Alternaria alternata and Cladosporium herbarum. Mol Immunol 1995; 32: 213-27.
[130] Wiszniewska M, Walusiak-Skorupa J, Pannenko I, et al. Occupational exposure and sensitization to fungi among museum workers. Occup Med 2009; 59: 237-42.

[131] Kobayashi T, Iijima K, Radhakrishnan S, et al. Asthma-related environmental fungus, Alternaria, activates dendritic cells and produces potent Th2 adjuvant activity. J Immunol 2009; 182: 2502-10.

[132] Chao HJ, Schwartz J, Milton DK, Burge HA. Populations and determinants of airborne fungi in large office buildings. Environ Health Perspect 2002; 110: 777-82.

[133] Haas D, Habib J, Galler H, et al. Assessment of indoor air in Austrian apartments with and without visible mold growth. Atmos Environ 2007; 41: 5192-201.

[134] Godwin C, Batterman S. Indoor air quality in Michigan schools. Indoor Air 2007; 17: 109-121.

[135] Aydogdu H, Asan A, Otkun MT, Ture M. Monitoring of fungi and bacteria in the indoor air of primary schools in Edrine city. Turkey. Indoor Built Environ 2005; 14: 411-25.

[136] Aydogdu H, Asan A. Airborne fungi in child day care centers in Edirne City, Turkey. Environ Monit Assess 2008; 147: 423-44.

[137] Stryjakowska-Sekulska M, Piotraszewska-Pajak SA, Nowicki M, Filipiak M. Microbiological quality of indoor air in University rooms. Polish J Environ Stud 2007; 16: 623-32.

[138] Uztan AH, Ateș M, Abaci O, et al. Determination of potential allergenic fungal flora and its clinical reflection in suburban elementary schools in Izmir. Environ Monit Assess 2010; 168: 691702 .

[139] Scheff PA, Paulius V, Conroy LM. Indoor air quality in a middle school, part II: Development of emission factors for particulate matter in a school. Appl Occup Environ Hyg 2000; 15: 835-42.

[140] Portnoy JM, Kwak K, Dowling P, Van-Osdol T, Barnes C. Health effects of indoor fungi. Ann Allergy Asthma Immunol 2005; 94: 313-20.

[141] WHO Guidelines for Indoor Air Quality: Dampness and Mould. In: Heseltine E, Rosen J, eds. World Health Organization. 2009.

[142] Rao CY, Burge HA, Chang JCS. Review of quantitative standards and guidelines for fungi in indoor air. J Air Waste Manage Assoc 1996; 46: 899-908.

[143] Wanner HU, Verhoff A, Colombi A, et al. Biological particles in indoor environments. European Collaborative Action "Indoor air quality and its impact on man". Commission of the European Communities, Report no. 12. Luxembourg, 1994.

[144] American Conference of Governmental Industrial Hygienists (ACGIH). Threshold limit values (TLVs) for chemical substances and physical agents and biological exposure indices (BEIs). Cincinnati, USA, 2009; pp. 223-6. [Available at www.acgih.o$\mathrm{rg} / \mathrm{TLV} / \mathrm{stu}$-dies.htm].

[145] Wong LT, Mui KW, Hui PS, Chan WY. Bayesian assessment for acceptable airborne bacteria levels in air-conditioned spaces. J Aerosol Sci 2007; 17: 80-6.

[146] Becher R, Honglso JK, Dybing E. Guidelines for indoor air in Norway - a practical approach. Poll. Atmos 2000; 166: 245-6.

[147] World Health Organization (WHO). Guidelines for concentration and exposure-response measurements of fine and ultra-fine particulate matter for use in epidemiological studies. Geneva, Switzerland, 2002.

[148] Jo WK Seo YJ. Indoor and outdoor bioaerosol levels at recreation facilities, elementary schools, and homes. Chemosphere 2005; 61: 1570-9.

[149] SUVA. Grenzwerte am Arbeitsplatz. Luzern, Switzerland, 2007.

[150] de Aquino Neto FR, de Góes Siqueira LF. Guidelines for indoor air quality in offices in Brazil. Proc Healthy Build 2004, 4; 549-54.

[151] Eduard W. Fungal spores: a critical review of the toxicological and epidemiological evidence as a basis for occupational exposure limit setting. Crit Rev Toxicol 2009; 39: 799-864.

[152] Occupational Safety and Health Administration (OSHA). Indoor air quality investigation. Technical Manual (OTM), Sect. II, chapter 2, 2008. [online www.osha.gov/dts/osta/otm/otm_iii//otm_iii_2.html\#text5].

[153] Institut für Arbeitsschutz der Deutschen Gesetzlichen Unfallversicherung (IFA ). Verfahren zur Bestimmung der Schimmelpilzkonzentration in der Luft am Arbeitsplatz (\#9420). Berlin, Germany, Erich Schmidt Verlag, 2001.

[154] Institut für Arbeitsschutz der Deutschen Gesetzlichen Unfallversicherung (IFA). Verfahren zur Bestimmung der Bakterienkonzentration in der Luft am Arbeitsplatz (\#9430). Berlin, Germany, Erich Schmidt Verlag, 2004. 
[155] World Health Organization (WHO). Indoor air quality: Biological contaminants. Copenhagen, European Series 1990; No. 31.

[156] Nevälainen A. Bacterial aerosols in indoor air. Dissertation, Helsinki, Finland, National Public Health Institute, 1989.

[157] Heida H, Bartma, F, van der Zee SC. Occupational exposure and indoor air quality monitoring in a composting facility. Am Ind Hyg Assoc J 1995; 56: 39-43.

[158] Oppliger A, Rusca S, Charriere N, Duc TV, Droz, PO. Assessment of bioaerosols and inhalable dust exposure in Swiss sawmills. Ann Occup Hyg 2005; 49: 385-91.

[159] Patuszka JS, Paw UKT, Lis DO, Wlazlo A, Ulfig K. Bacterial and fungal aerosol in indoor environment in Upper Silesia, Poland. Atmos Environ 2000; 26: 2149-62.
[160] Jones AM, Harrison RM. The effects of meteorological factors on atmospheric airborne bioaerosol concentrations. Sci Total Environ 2004; 28: 3125-30.

[161] Nunes ZG, Martins AS, Altoe ALF, et al. Indoor air microbial evaluation of offices, hospitals, industries, and shopping centers. Mem Inst Oswaldo Cruz 2005; 100: 351-7.

[162] Molongoski JJ, Klug MJ. Characterization of anaerobic heterotrophic bacteria isolated from freshwater lake sediments. Appl Environ Microbiol 1976; 31: 83-90.

[163] Barriuso J, Ramos Solano B, Lucas JA, et al. Ecology, genetic diversity and screening strategies of plant growth promoting rhizobacteria (PGPR), In: Ahmad I, Pichel J, Hyat S. Eds. Plantbacteria interactions: Strategies and techniques to promote plant Growth. Weinheim: John Wiley \& Sons, 2008; pp. 1-17.

(C) Mandal and Brandl: Licensee Bentham Open.

This is an open access article licensed under the terms of the Creative Commons Attribution Non-Commercial License (http://creativecommons.org/licenses/ by-nc/3.0/) which permits unrestricted, non-commercial use, distribution and reproduction in any medium, provided the work is properly cited. 